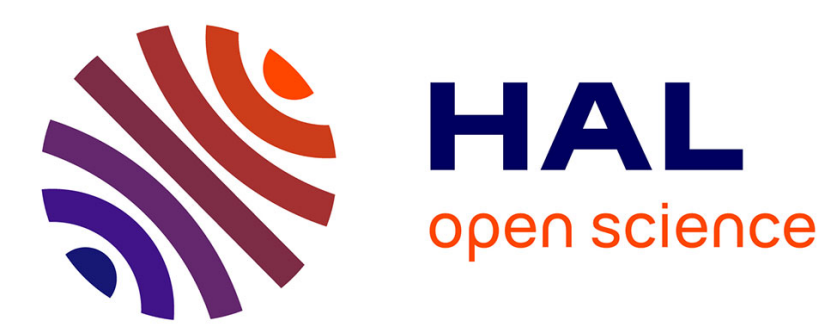

\title{
Ongoing Research on Pesticides Air Dispersion
}

\author{
B. Bonicelli, Eric Cotteux, C. Sinfort, B. Ruelle, V. de Rudnicki
}

\section{To cite this version:}

B. Bonicelli, Eric Cotteux, C. Sinfort, B. Ruelle, V. de Rudnicki. Ongoing Research on Pesticides Air Dispersion. CIGR-Ageng 2012. International Conference on Agricultural Engineering, Jul 2012, Valencia, Spain. 6 p. hal-00825458

\section{HAL Id: hal-00825458 https://hal.science/hal-00825458}

Submitted on 23 May 2013

HAL is a multi-disciplinary open access archive for the deposit and dissemination of scientific research documents, whether they are published or not. The documents may come from teaching and research institutions in France or abroad, or from public or private research centers.
L'archive ouverte pluridisciplinaire HAL, est destinée au dépôt et à la diffusion de documents scientifiques de niveau recherche, publiés ou non, émanant des établissements d'enseignement et de recherche français ou étrangers, des laboratoires publics ou privés. 


\title{
Ongoing Research on Pesticides Air Dispersion
}

\author{
B. Bonicelli ${ }^{1 *}$, E. Cotteux ${ }^{1}$, C. Sinfort ${ }^{2}$, B. Ruelle ${ }^{1}$, V. De Rudnicki ${ }^{1}$, \\ ${ }^{1}$ UMR ITAP, 361 rue Jean-François Breton, 34196 Montpellier France \\ ${ }^{2}$ UMR ITAP, 2 place Pierre Viala, 34060 MONTPELLIER Cedex 02 \\ *Corresponding author. E-mail: bernard.bonicelli@irstea.fr
}

\begin{abstract}
:
Air contamination by Plant Protection Products (PPPs) carries significant risks for human health. Crop protection spraying induces air contamination, mainly in fruit production. In 2001, observations showed important transfers during and after spraying (direct losses vs. volatilization from soil and crop), downwind a productive vineyard. At the human scale the resulting exposure is difficult to measure because the PPPS concentration vary greatly in space and time. In consequence, researches are focused on coupling simulation tools and data to estimate properly the air contamination. Experimentations are conducted at fieldscale and labscale. The objective is to improve the methodology on air sampling and to develop analysis tools dedicated to population protection and spraying optimisation recommendation.
\end{abstract}

Keywords: pesticides, air, dispersion, human exposure

\section{Introduction}

\subsection{Risks for human health}

Health risk is the probability, or chance, that exposure to hazardous substance will make you sick. Experimentations provide information about how hazardous a substance is. Scientists use the results of such studies to estimate the likelihood of illness at different levels of exposure.

\subsection{Air monitoring}

Information on exposure comes from two places: monitoring tools and mathematical models that estimate exposure based on chemicals released amounts. This information resource is generally dedicated to urban or peri-urban area and mid term observations: day, week or month. In France, air quality monitoring is carried by the Official Air Quality Monitoring Associations (AASQA) using forecasting tool (Rouil at al, 2009). For rural areas AASQA conducts monitoring campaigns on pesticides in the air since 2000. The main French agricultural regions have been monitored.

\subsection{Bystanders exposure}

In agriculture, spraying induces air contamination with direct losses during application and volatilisation mechanisms after application. Depending on concentration and toxicity, inhalation of Plant Protection Products (PPPs) carries significant risks to bystanders and workers. For each situation, agrochemical exposure results in a set of interactions: compounds characteristics, spraying set up, weather conditions, distance (Gil, 2007). As a consequence, PPPs concentration can vary greatly in space and time.

\subsection{Spraying optimization}

Recent studies show a significant potential for reducing pesticide use (Bonicelli et al, 2010). Precision Farming (PF), provides methods and tools to optimize agriculture practices: 
adjustment of dose, retrofit of air-blast sprayers to canopy density, sensors to adjust the spray to canopy shape or slope, recording tools to analyse the practices (DeRudnicki, 2010). At least, the containment of sprays (cf. recovery panels) can eliminates almost all the air and soil losses, up to $90 \%$. But in all cases the air pollution remains possible through volatilisation mechanisms in post application (Bedos, 2002).

\subsection{Research strategy}

Improving knowledge on exposure pathways is a key point to reduce the potential risks and improve the spraying practices.

As shown previously, classical monitoring tools are not suitable to study bystander exposure. In consequence, researches and developments are focused on coupling short distance simulation tools and data sets to estimate properly the dynamics of the air contamination. Experimentations are conducted at fieldscale and labscale using fluorescent dye and gas molecule as tracer. Quantification of those different tracers has been made help to classical spectrofluorimeter method and help to an original electrochemical sensor. This paper presents the on going knowledge on air monitoring and the research tools used: (i) air sampling, (ii) simulation tools (iii) experimentation and test programs.

\section{Monitoring}

In 2001, (Marlière, 2002) a first set of tests was carried out in a vineyard with the aim to assess the ability to detect pesticides in the air, downwind the application zone. The test was achieved on a "Cordon de Royat" vineyard (in the North of Montpellier) featured by a layout of $2.5 \mathrm{~m} \times 2.5 \mathrm{~m}$ and an average height of $2.0 \mathrm{~m}$ (Fig. 1). The sprayer was a "pneumatic" Tecnoma Pulsar 800L with 4 tapered Jet guns and 2 fingers hands. The spraying characteristics were the following:

- Forward Speed: 3,6km/h

- Average wind speed and Temperature: $2 \mathrm{~m} / \mathrm{s}-20^{\circ} \mathrm{C}$

- Droplets size: 80 to $200 \mu$

- Spraying flow rate $144 \mathrm{l} / \mathrm{ha}-3,5 \mathrm{l} / \mathrm{mn}$

- Spraying pressure: $1.5 \mathrm{bars}$

- PPPs : Folpel (480 g/l)

The air samplers were placed at a height of $2.0 \mathrm{~m}$ from the ground and situated along the downwind NW-SW direction. Two different samplers were compared:

- Digitel $40 \mathrm{~m} 3 / \mathrm{h}, 12 \mathrm{~h}$ manual sampling, 300m and $1500 \mathrm{~m}$ downwind the field

- Partisol 1m3/h, 24h automating sampling, 1500m downwind the field

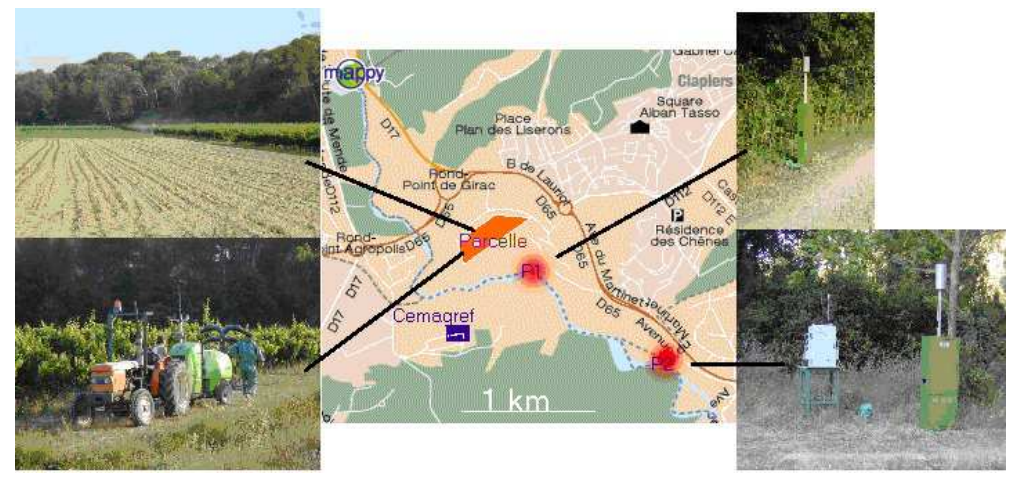

Fig.1: testing site and equipment (Cemagref/Ineris 2001) 
Tests occured in June during 4.5 days with a vineyard treatment on the 27/06 am. During and after spraying, observations, showed significant concentration of PPPs in the air. In Fig. 2 , it can be noticed the Folpel concentration over $150 \mathrm{ng} / \mathrm{m} 3$ near the field and $40 \mathrm{ng} / \mathrm{m} 3 \mathrm{up}$ to $1500 \mathrm{~m}$ during the treatment and including a $12 \mathrm{~h}$ sampling period. Concentration in the 3 hours related spraying time is estimated to be greater than $600 \mathrm{ng} / \mathrm{m} 3$ and $200 \mathrm{ng} / \mathrm{m} 3$ respectively at field side and up to $1500 \mathrm{~m}$ downwind.

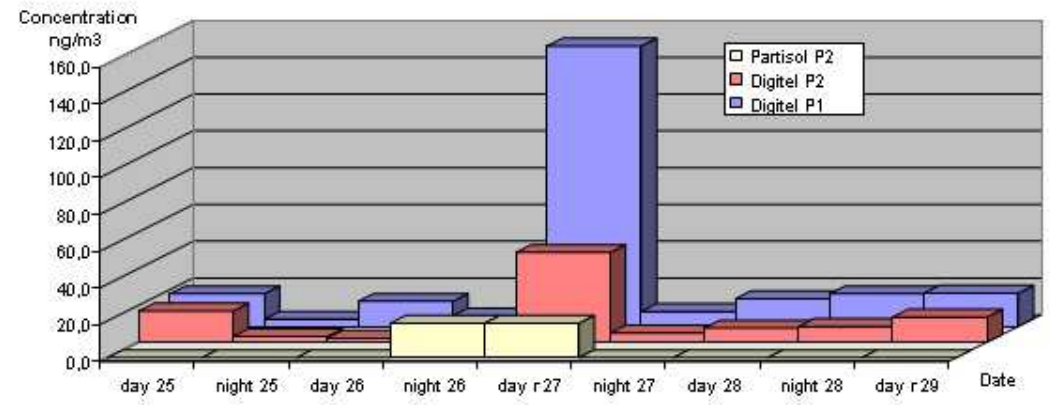

Fig.2: PPPs concentration in the air (Cemagref/Ineris 2001)

These results can be interestingly compared to the maximum level reported by the French Pesticides Residues Observatory (ORP) in the 2001-2006 synthesis report (ANSES, 2010) which indicates a maximum of $82,22 \mathrm{ng} / \mathrm{m} 3$ per week at the national scale (based on 1268 observations).

\section{Simulation}

In France, the PREV'AIR quality maps (Rouil, 2009) are published every day elaborated through numerical simulations based on Eulerian chemistry-transport models. That allows the calculation of the evolution of photochemical pollution in the lower layer of the atmosphere on different spatial scales. The spatial resolution of these deterministic threedimensional models varies in accordance with the geographical extension of the areas: $4^{\circ}$ for the Global scale $0.5^{\circ}$ for the European scale, $0.1^{\circ}$ for the National Scale. It is not sufficient to estimate local exposure at the human scale.

At this scale cemagref/Irstea developed an original simulation low complexity model named DRIFTX based on Gaussian dispersion and including GIS visualisation tools (Fig. 3 - Bozon, $\underline{2008}$ ).

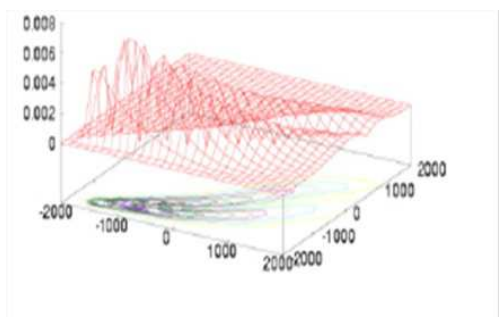

(a) typical Gaussian dispersion

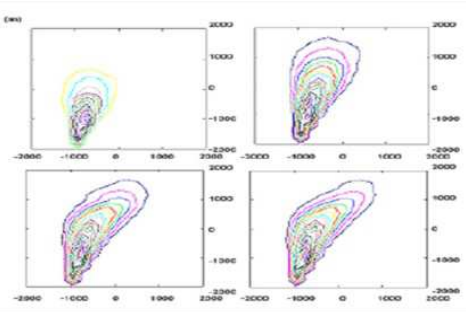

(b) time response

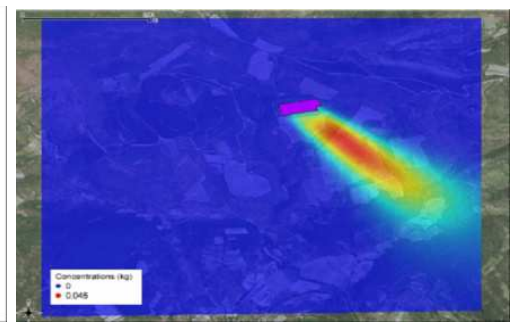

(c) GIS Visualisation

Fig.3: Drift X simulation tool (Cemagref 2009) 


\subsection{Experimentations}

Two complementary trials are conducted to improve the current knowledge on pesticides dispersion in air (Fig. 4). A first set of test will be done in field to improve air sampling. A second test is done in the climatic wind tunnel of Montpellier to validate the simulation tool. All the site tests are used for demonstration.

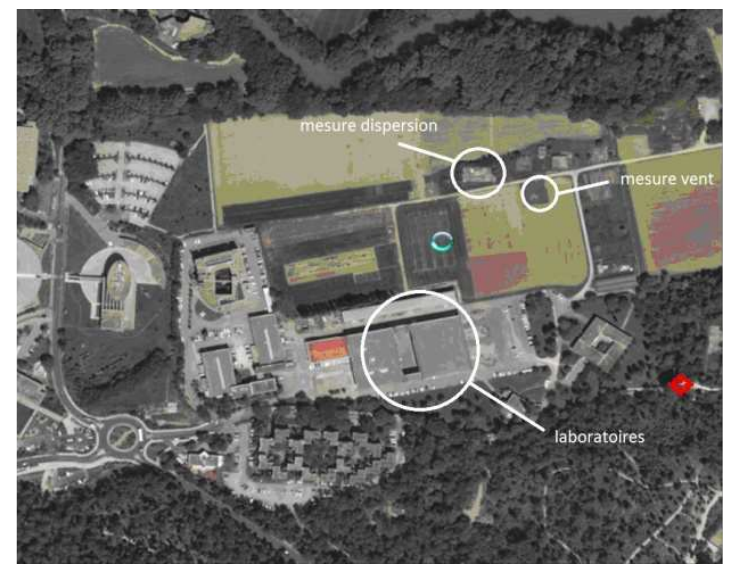

Fig.4: Field and Lab testing Site (Irstea 2012)

\subsection{Field validation and demonstration}

The field experimentation is carried out in an artificial vineyard situated in the Montpellier's Irstea Site (Fig. 5). The artificial vineyard is featured by 4 rows on a $10 \mathrm{~m} \times 10 \mathrm{~m}$ surface. The height of each row is $2.0 \mathrm{~m}$ and the thickness is $0.5 \mathrm{~m}$. Dispersion is characterised using the brilliant Sulfo Flavine (BSF) yellow tracer dye and/or Hydrogen Sulfide (H2S) dissolved in natural thermal waters.

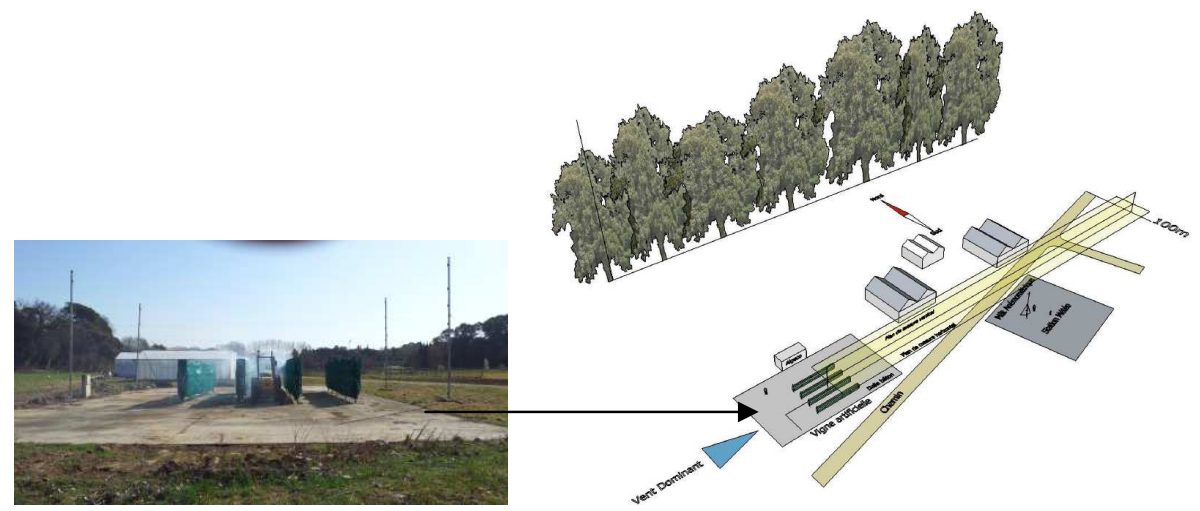

Fig 5: experimental tests on artificial vines (source: Irstea 2012 )

A $6 \mathrm{~m}$ height meteorological mast equipped with 3 three dimensional ultrasonic anemometer young model 81000 allowed to determine optimal experimental conditions Each test is performed when adequate meteorological conditions: wind below $1 \mathrm{~m} / \mathrm{s}$, in parallel to the vineyard row direction, with no thermal convection, and no turbulence. Air monitoring is implemented trough a set of 25 wireless electrochemical sensors up to $100 \mathrm{~m}$ down wind the main wind in the West East direction. Spraying is characterised near the artificial wind with passive sampler: wires and plates for air and soil losses, artificial canopy for leaves deposits. This includes a mass balance to define the Dispersion Source Term (Fig. 6): 


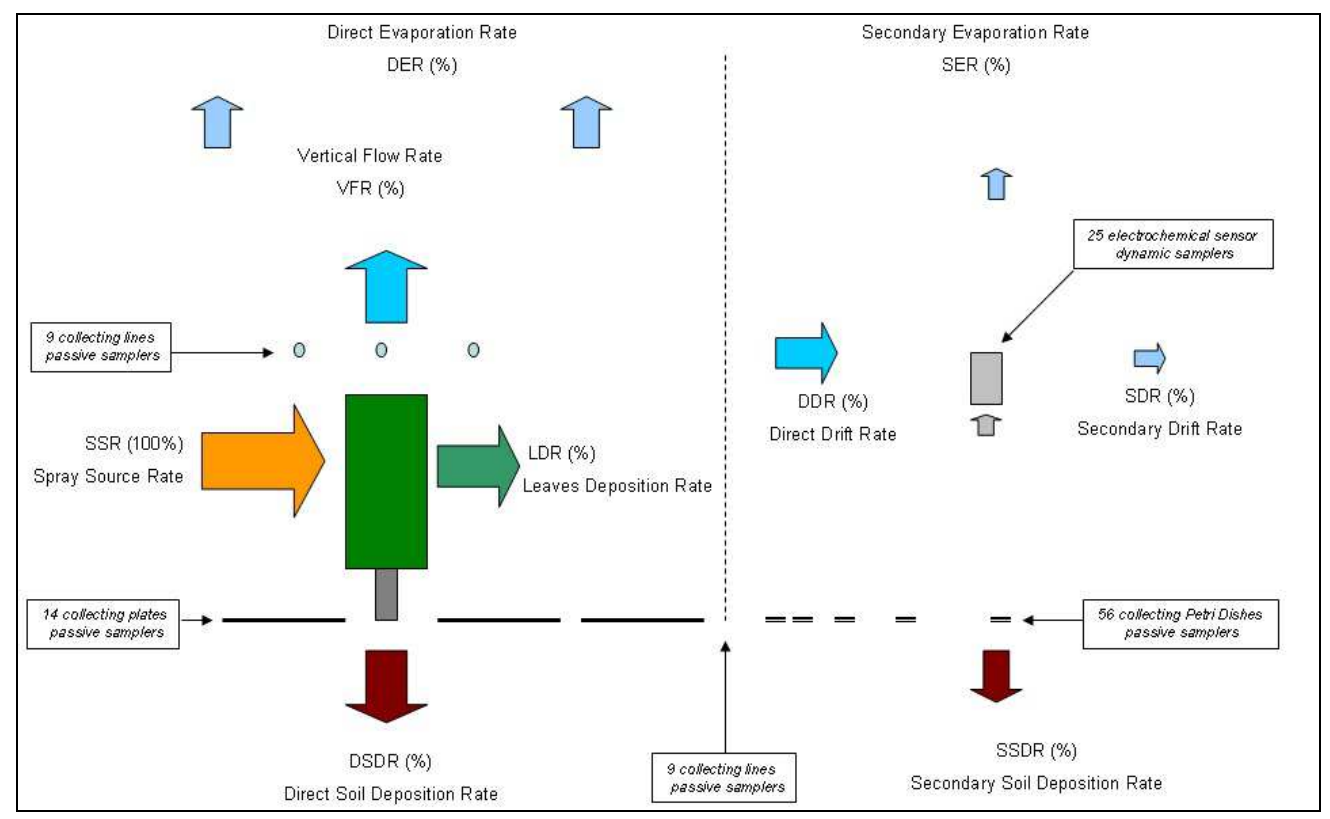

Fig 6: mass balance parameters (source: Irstea 2012 )

The mass balance for physical equilibrium becomes

$$
\begin{aligned}
& \text { (1) } S S R=S S D+L D R+V F R \\
& \text { (2) } D D R=V R+D E R=S S D+S D R+S E R
\end{aligned}
$$

The inhalation exposure includes liquid phase (droplets) and vapour phase (gaz). Classical air sampler and dynamics sensors are featured to measure the average and the instantaneous exposure.

\subsection{Laboratory developments}

The laboratory trials are carried out in the IRSTEA climatic wind tunnel (Fig.7). The tunnel is $2 \mathrm{~m}$ height, $3 \mathrm{~m}$ width and $12 \mathrm{~m}$ length. At the $1 / 10$ scale the scene simulates a dispersion distance of $120 \mathrm{~m}$, in correspondence with the field test.

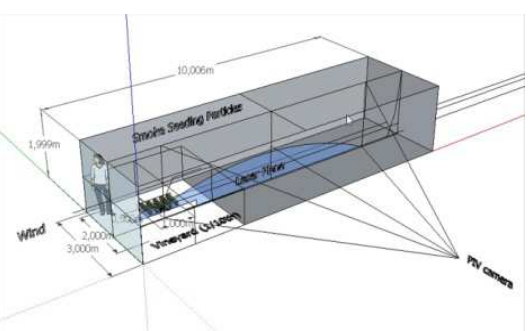

(a) Wind Tunnel Tests

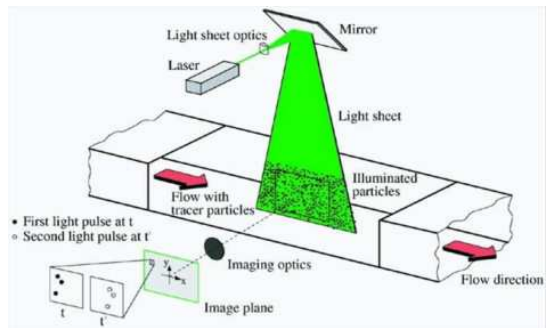

(b) Particle Image Velocimetry

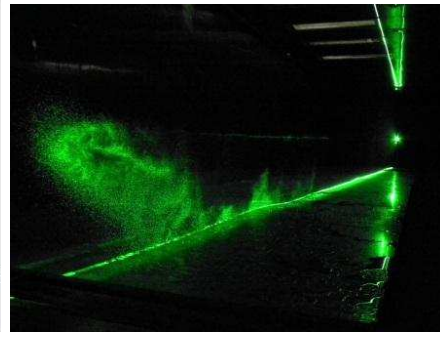

(c) Dispersion Visualisation

Fig. 7: laboratory experimentation (Irstea 2012)

As for field tests, the measurement includes passive samplers to achieve mass balance and dynamic samplers to determine the tracer dye concentration in the air. In addition, image analysis tools and laser light are used to achieve the droplets dynamics. 


\section{Conclusion}

This original research approach allows combining fieldscale and labscale level analysis to develop a very innovative tool to predict or at least to estimate peak exposure during agricultural spraying operation. The development includes simulation and experimentation to improve PPPs human exposure characterisation. The original gas sensors used is based on previous researches (passive and dynamic sampling), and the methodology are innovative. At a local scale, the coupling of model and monitoring makes it possible to characterise the bystanders chronic exposure to PPPs by inhalation. Moreover, several domains can be interested in those results especially when nasty smell can be produced during specific operations.

\section{Acknowledgements}

The project is funded by the Regional Council (Languedoc-Roussillon) and the European Regional Development Fund (FEDER) to promote research transfers to regional companies.

\section{Reference list :}

Bedos C., Cellier P., Calvet R., Barriuso E., 2002. Occurrence of pesticides in the atmosphere in France. Agronomie, 22, 35-49.

Marliere F. (2002). Pesticides dans l'air ambiant. Rapport INERIS DRC 02-39271 AIRE 781/FMr. 66 pages.

Gil Y., Sinfort C., et al. (2007). Atmospheric loss of pesticides above an artificial vineyard during air assisted spraying. Atmospheric Environment. 41: 2945-2957.

Bozon N., B. Mohammadi B., et al. (2008). "Similitude and non symetric geometry for dispersion modelling." e-STA Sciences et Techniqles de l'Automatique 5(2): 182-192.

De Rudnicki V., Ruelle B., et al. (2010). "Embedded NICT* tools and traceability to control phytochemical treatments." Ageng 2010, Clermont-Ferrand: 11 pages.

Bonicelli,B., Naud O., et al. (2010). "The challenge for precision spraying" AGENG 2010, Clermont Ferrand: 11 pages.

Rouil L. et al (2009). "PREV'AIR : an operational forecasting and mapping system for air quality in Europe. " Bulletin of the American Meteorological Society, 2009, vol. 90, n¹, pp. 73-83.

ANSES (2010). "Recommandations et perspectives pour une surveillance nationale de la contamination de l'air par les pesticides: synthèse et recommandations du comité d'orientation et de prospective scientifique de l'observatoire des résidus de pesticides (ORP)". Rapport scientifique de l'ANSES d'octobre 2010, 48 pages. 